\title{
Conditioning of Praziquantel and Florfenicol for some Heterologous Coinfections of Farmed Carp
}

\author{
ANDREI CRISTIAN LUPU', MIHAELA BOMBOS²*, CRISTIAN ALIN BARBACARIU³, CONSTANTIN ROMAN', RALUCA MINDRU, \\ GABRIELA VICTORIA MARTINESCU1, LIVIU DAN MIRON* \\ 'University of Agricultural Sciences and Veterinary Medicine Ion Ionescu de la Brad, Faculty of Veterinary Medicine, $8 \mathrm{M}$. \\ Sadoveanu Alley, 700489, Iasi, Romania \\ 2The National Institute for Research \& Development in Chemistry and Petrochemistry, 202 Splaiul Independenei 202, 060021, \\ Bucharest, Romania \\ ${ }^{3}$ Research and Development Center for Aquaculture and Aquatic Ecology, Iasi-Ciurea Road, 700669, Iasi, Romania
}

Coinfections can alter the course and severity of different fish diseases. Suspensions of praziquantel (PZQ) and florfenicol (FFC) based on sunflower oil can be an effective alternative for treating fish coinfections. The use of polyoxyethylene (20) sorbitan monooleate in the presence of ethoxylated castor oil in the preparation of $P Z Q$ and FFC suspensions has improved the stability of these suspensions. This $P Z Q$ and FFC preparation can be used in the treatment of parasitic/bacterial heterologous coinfections. The suspension of the $P Z Q$ and FFC preparation can be administered by water-diffusion, having a controlled release. The compounds are biodegradable and the route of administration remains safe for the environment.

Keywords: coinfections, conditioning, praziquantel, florfenicol, controlled release

The subject of co-infected aquatic animals by different pathogens has received little attention, even though these infections are common in nature. Coinfections (CO) are defined by infection of the host by two or more different genetic pathogens, where each pathogen has pathogenic effects and causes harm to the host in coincidence with other pathogens [1]. Several other terms are used once to describe $\mathrm{CO}$ and include polymicrobial diseases, complicated infections, concomitant infections, mixed infections, multiple infections, double infections, secondary infections and super-infections [2].

Many researchers have only focused on unique infections, classifying the other agent as opportunistic and ignoring it in most cases, so in this report we will focus on distinguishing infections caused by several organisms. During COepisodes, interactions between infectious agents lead to varying results: the loading of one or both pathogens may be increased, one or both can be suppressed or can be increased and the other suppressed [3]. The natural environments in which animals live are varied and contain a variety of heterogeneous microorganisms, including parasitic and non-parasitic species, and coinfection isa common phenomenon. There is therefore a considerable need to investigate the interactions that occur between these species during mixed infections and the harmful effects of multi-infections on the pathogenesis, prognosis and treatment of fish diseases [4].

Parasitic infections increase the risk of secondary bacteria and can act as a vehicle for transmitting bacterial pathogens [5]. This synergistic interaction has been demonstrated by numerous experimental studies [6], which showed increased mortality rates in parasitic/ bacterial $[7,8]$, explained this synergistic effect who was as a result of stress caused by parasites reducing the resistance of fish to other bacterial secondary infectionsby, as well as the harmful effects caused by the parasite that offered the invasion of bacteria with an entry pathway. In some cases, parasites catch the bacteria and deliver them to their host while nourishing [9].
Increased attention should be directed to preventing parasitic infection in fish to reduce fish mortality due to bacterial secondary infection.

In this paper we focused on the monogenous skin trematode infestation observed in bacterial co-infected carp farms, as well as the attempt to condition praziquantel (PZQ) and florfenicol (FFC). This has been done to evaluate the efficacy of these conditioned drugs using an improved oral administration method.

Praziquantel (PZQ) is widely used as a chemotherapeutic agent for the treatment of helminths in fish farms. It is effective against monogens that infect the gills, skin and gill cavities [10], occluded larvae and digesties [11] and skin [12] and intestinal tracts [13] of the fish.

Carp fish (Cyprinus carpio) is an economically important species of farmed fish. In Romania, carp has a wide spread in aquaculture, covering different areas in eastern and north-western regions and freshwater areas in central and southern regions. Several studies have shown that the salinity of the water in the environment can influence the accumulation and elimination of fish chemicals. The difference in pharmacokinetics influences the efficacy of PZQ in aquaculture, especially for the treatment of monogenic infestations in farmed carp.

Florfenicol is a thiamphenicol derivative with the same mechanism of action as chloramphenicol (inhibition of protein synthesis). How ever, it is more active than chloramphenicol or thiamphenicol and may be more bactericidal than previously thought against pathogens. Florfenicol has a broad spectrum of antibacterial activity that includes all organisms sensitive to chloramphenicol, gram-negative bacilli, gram-positive cocci and other atypical bacteria such as mycoplasma. Florfenicol is very lipophilic, providing sufficient concentrations for the treatment of intracellular pathogens and crossing some anatomical barriers (penetration of the haematoencephalic barrier) [14].

The pharmacokinetics of the drug in aquatic animals may be affected by various environmental factors such as water temperature, $\mathrm{pH}$ and salinity. However, salinity is 
often neglected, especially in freshwater fish. Moreover, to improve the quality of carp muscles, fish are often placed in salt water for a period of time before harvesting.

Praziquantel (PZQ) is an anthelmintic commonly used for some parasites in humans and animals, such as schistosomiasis. The drug is also used to treatfish parasites and approved for use in aquaculture against Benedenia seriolae, a locus in the tegument of Seriola lalandi. Oral administration of PZQ, commonly mixed with commercial food granules, proves to be effective against some fish parasites, including $B$. seriolae and Neobenedenia girellae $[15,16]$.

However, PZQ is extremely bitter and has a low palatability for fish, which makes oral administration difficult $[17,18]$. Therefore, the feeding technique should be re-evaluated for the practical use of $P Z Q$ in aquaculture. In addition, PZQ efficacy may be different between parasite species and between host fish [19], so drug evaluation should be performed using the host/parasite target system.

Florfenicol (FFC) is a semi-synthetic antibacterial agent with a chemical structure and spectrum of antibacterial activity similar to thiamphenicol. Both florfenicol and thiamphenicol are analogs of chloramphenicol wherein the p-nitro group in the aromatic ring is substituted with a sulfonylmethyl group. Florfenicol and thiamphenicol are not associated with toxic side effects as shown for chloramphenicol. The bacteria are resistant to chloramphenicol and thiamphenicol due to the production of the drug inactivation enzyme, namely acetyltransferase, which is susceptible to florfenicol [12]. Florfenicol binds to the bacterial $50 \mathrm{~S}$ ribosomal subunit and inhibits protein synthesis at the peptidyl transferase stage. In vitro investigations with florfenicol have demonstrated strong activity against several pathogenic bacteria for fish. In vivo efficacy against furunculosis in Atlantic salmon and classical vibriosis in cod was demonstrated [17]. Yersinia ruckeri, how ever, appears to have a natural resistance against this agent [19]

The bacterial resistance to florfenicol can be mediated by both chromosomal and plasmid genes. The magnitude of resistance to fish pathogens is generally unknown, butit has been reported that despite the widespread use, florfenicol resistance does not appear to occur frequently [16].

The presentstudy was designed to evaluate conditioned florfenicol and praziquantel and to establish a drug formula able to eliminate some parasitic and bacterial coinfections, especially from the tissue through a controlled distribution to common carp.

\section{Experimental part}

The surfactant compounds used to stabilize these suspensions are $20 \mathrm{EO}$ polyethoxylated sorbitan monooleate (Polysorbate80 Aldrich - Tween 80), sodium-laurylether-sulfate (trade name EMAL ${ }^{\circledR} 270 \mathrm{D}$ ), castor oil ethoxylated (Leunapon-ERx), ethoxylated propoxylated C12-C14 fatty alcohol: Leunapon-F 1214/x/Py (Alc1) and C12-C14 fatty alcohol ethoxylat: Leunapon-F 1214/x (Alc 2). Sorbic acid and the medicines praziquantel (99\%) and florfenicol (98\%) were purchased from Sigma-Aldrich.

Stabilizing the suspension of the two drugs involves reducing their size in order to diminish the deposition trend. In order to reduce the particle size, a planetary ball mill was used (Fritsch Pulverisette 6) equipped with a stainless steel pot of $500 \mathrm{~mL}$ capacity and 10 stainless steel balls with a diameter of $20 \mathrm{~mm}$, weighing $30 \mathrm{~g} / \mathrm{ball}$. The grinding experiments in the planetary ball mill were performed ata $1 / 3$ solid mass / ball ratio, at 500 rpm with 10 balls of steel for $30 \mathrm{~min}$. The milling process was wet and was conducted in the presence of sorbic acid and two antiagglomeration additives, sunflower oil (samples P1 and F1) and ethoxylated castor oil, respectively (samples P2 and F2).

In order to characterize the ground solids, they were suspended in a non-polar solvent. The dimensions of the prepared particles and the distribution of their dimensions were determined using a particle size measurement system by dynamic light scattering (DLS) with a MalvernZetasizer NanoZS instrument (Red badge). For this purpose, the samples were dispersed in heptane at a concentration of $1.6 \mathrm{~g} / 100 \mathrm{~mL}$ of solvent.

The water dispersion of the two drugs is aimed at obtaining high stability suspensions which, by dosing in water, allow a uniform distribution of these drugs in the respective water basins. The preparation of the suspensions was carried out by atomizing two phases: the aqueous phase containing surfactants and the organic phase containing the suspension of drug and sorbic acid milled and diluted in an oily phase (sunflower oil or ethoxylated castor oil).

In the first stage the drug and sorbic acid, previously ground in the oil phase (sunflower oil or ethoxylated castor oil), are dispersed in this hydrophobic phase. The emulsifiers are added to the water with agitation using an UltraTurax shaker (IKA). The dispersion in ethoxylated oil is gradually added over the aqueous phase under stirring at $3000 \mathrm{rpm}$. The formed suspension is maintained at 8000 rpm for $30 \mathrm{~min}$.

The stability over time of dispersed systems, such as drug suspensions, was evaluated by the dynamic light scattering method. A TurbiscanLab appliance was used with dedicated software for recording and interpreting data: Turbisoft Formulaction. The analyzed sample is introduced into a dedicated cylindrical glass vessel scanned at predetermined time intervals with a wavelength of 880 $\mathrm{nm}$ in the air. Two optical sensors (fig. 1), properly disposed, receive light transmitted through the sample (detector set at $180^{\circ}$ to the light source) or diffuse scattered light (detector disposed at $45^{\circ}$ from the light source).

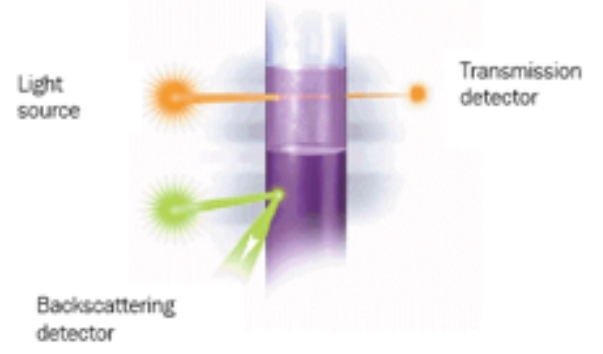

Fig. 1. The principle of measuring the method using TurbiscanLab

The sample to be analyzed is introduced into a cylindrical glass analysis cell. The equipment scans vertically the sample subjected to the $20 \mu \mathrm{m}$ resolution using a beam of light. It is provided with a combination of sensors that simultaneously record values for light transmission, useful for transparent samples, and for light diffusion (opaque samples), thus detecting any phenomenon of destabilization of the analyzed compositions.

\section{Results and discussions}

The DLS analysis of the two samples of florfenicol is shown in figures 2 and 3 and in tables 1 and 2 . From figure 1 it is observed that following the grinding of florfenicol in the presence of ethoxylated castor oil, particles with low sizes and with a bimodal particle size distribution. 


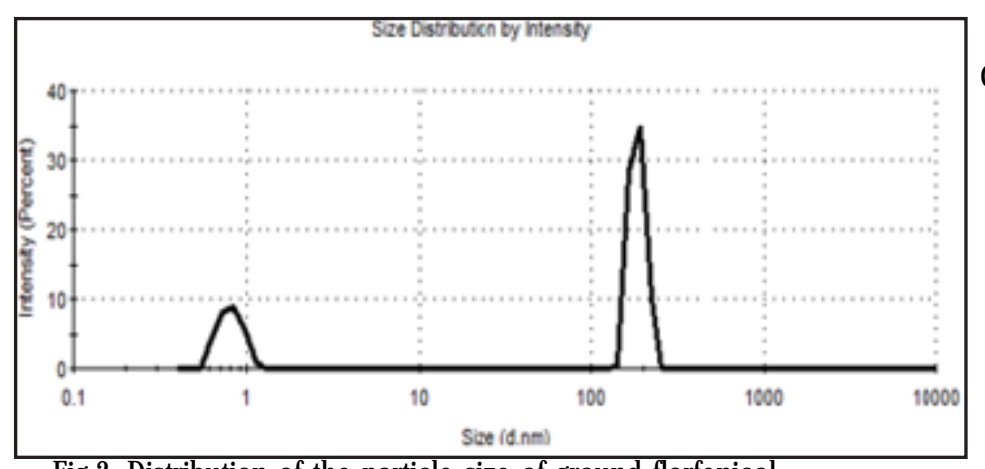

Table 1

CHARACTERISTICS OF MILLED FLORFENICOL PARTICLES IN THE PRESENCE OF ETHOXYLATED CASTOR OIL

\begin{tabular}{|c|c|c|}
\hline Peak & Dm, nm & Peak intensity, \% \\
\hline P1 & 0.8028 & 26.8 \\
\hline P2 & 184.1 & 73.2 \\
\hline
\end{tabular}

Fig.2. Distribution of the particle size of ground florfenicol in the presence of ethoxylated castor oil

Table 1 shows the average diameter of the ground florfenicol particles in the presence of ethoxylated castor oil and the intensity of the two peaks.

Thus, it is observed that the P1 sample of florfenicol exhibits a bimodal distribution with a roughly three-fold higher peak intensity with an average diameter of $184 \mathrm{~nm}$ with respect to the median peak of $0.8028 \mathrm{~nm}$.

From figure 3 it is observed that after the florfenicol was milled in the presence of sunflower oil a unimodal distribution of particle size was obtained. The diameter of the florfenicol particles varies over a much narrower range than in the case of milling in the presence of ethoxylated castor oil.

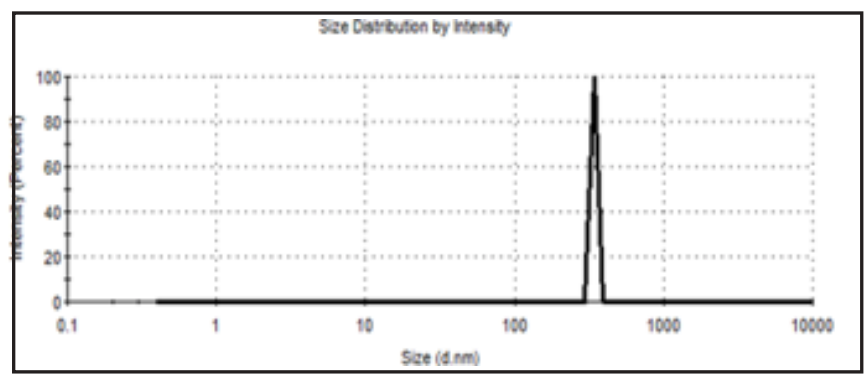

Fig.3. Distribution of particle size of ground florfenicol in the presence of sunflower oil

Table 2 shows the average diameter of milled florfenicol particles in the presence of sunflower oil.

Table 2

CHARACTERISTICS OF MILLED FLORFENICOL PARTICLES IN THE PRESENCE OF SUNFLOWER OIL

\begin{tabular}{|c|c|c|}
\hline Peak & Dm, $\mathrm{nm}$ & Peak intensity, \% \\
\hline P1 & 342.0 & 100.0 \\
\hline
\end{tabular}

It is noted that the mean diameter of the florfenicol particles is much higher than in the case of grinding in the presence of ethoxylated castor oil.

The DLS analysis of the two praziquantel samples is shown in figures 4 and 5 and in tables 3 and 4 . From Figure 4 it is observed that after the milling of praziquantel in the presence of sunflower oil there were obtained particles larger than in the case of the sample of florfenicol, ground in the presence of the same additive. Also, unlike the florfenicol particles, particle size distribution is unimodal and not bimodal.

The mean diameter of the praziquantel particles ground in the presence of sunflower oil is shown in table 3 . It is noted that the praziquantel particles have a larger average diameter than the sample of florfenicol, ground in the presence of the same additive.

The DLS analysis of the ground praziquantel sample in the presence of ethoxylated castor oil is shown in figure 5 and table 4 . It can be seen from figure 5 that the milling of

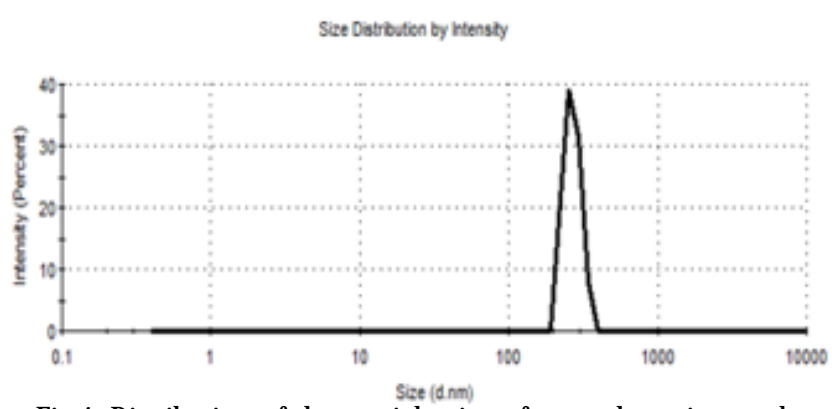

Fig.4. Distribution of the particle size of ground praziquantel in the presence of sunflower plant oil

Table 3

CHARACTERISTICS OF MILLED PRAZIQUANTEL PARTICLES IN THE PRESENCE OF SUNFLOWER OIL

\begin{tabular}{|c|c|c|}
\hline Peak & Dm, nm & Peak intensity, \% \\
\hline P1 & 267.3 & 100.0 \\
\hline
\end{tabular}

praziquantel in the presence of ethoxylated castor oil resulted in particle sizes with a larger range than in the case of praziquantel ground in the presence of sunflower oil. Also, the particle size distribution is unimodal as in the case of praziquantel ground in the presence of sunflower oil.

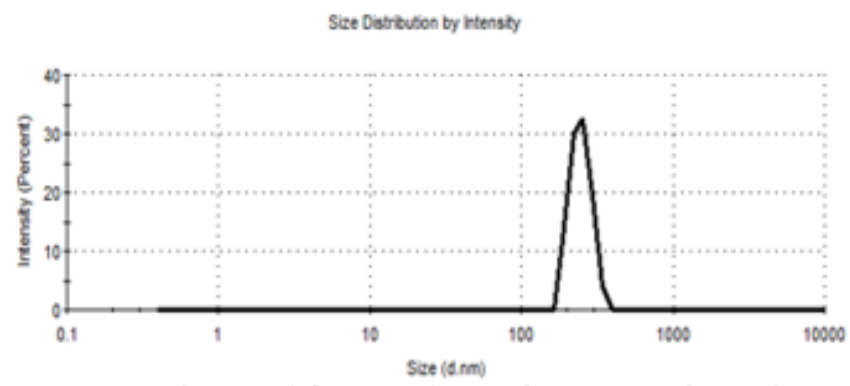

Fig.5. Distribution of the size of ground praziquantel particles in the presence of ethoxylated castor oil

Table 4 shows that the praziquantel particles have a lower average diameter than the ground praziquantel sample in the presence of sunflower oil.

DLS analysis of the four samples reveals two types of particle size distributions: bimodal distribution in the case of ground florfenicol sample in the presence of sunflower oil and unimodal distribution for the other three samples.

The mean diameter of the ground praziquantel particles was greater than that of the florfenicol samples.

Table 4

CHARACTERISTICS OF MILLED PRAZIQUANTEL PARTICLES IN THE PRESENCE OF ETHOXYLATED CASTOR OIL

\begin{tabular}{|c|c|c|}
\hline Peak & Dm, nm & Peak intensity, \% \\
\hline P1 & 246.8 & 100.0 \\
\hline
\end{tabular}




\begin{tabular}{|c|c|c|c|c|c|c|c|c|}
\hline \multirow[t]{2}{*}{ Sample } & \multicolumn{8}{|c|}{ Component, g } \\
\hline & Praziquantel & $\begin{array}{l}\text { Sorbic } \\
\text { Acid }\end{array}$ & Oil & $\begin{array}{c}\text { Distilated } \\
\text { water }\end{array}$ & $\begin{array}{c}\text { Tween } \\
80\end{array}$ & Alc $1^{*}$ & EMAL & Alc $2^{\text {tx }}$ \\
\hline Pp1 & 3.2 & 0.3 & 15.0 & 78.5 & 3.0 & 0 & 0 & 0 \\
\hline $\mathrm{Pp} 2$ & 3.2 & 0.3 & 15.0 & 78.5 & 0 & 0 & 2.0 & 1.0 \\
\hline $\mathrm{Pp} 3$ & 3.2 & 0.3 & 15.0 & 78.5 & 2.0 & 1.0 & 0 & 0 \\
\hline
\end{tabular}

Table 5

RECIPES USED

TO PREPARE

PRAZIQUANTEL

AQUEOUS

SUSPENSIONS

Alc $1^{*}$ ethoxylated propoxylated C12-C14 fatty alcohol;

Alc 2": Cl2-C14 fatty alcohol ethoxylate.

\begin{tabular}{|c|c|c|c|c|c|c|c|c|}
\hline Sample & \multicolumn{7}{|c|}{ Component, g } \\
& Florfenic0l & Sorbic Acid & Oil & $\begin{array}{c}\text { Distilated } \\
\text { water }\end{array}$ & $\begin{array}{c}\text { Tween } \\
80\end{array}$ & Alc 1 & EMAL & Alc 2 \\
\cline { 2 - 9 } & & & & & & & & \\
\hline Pf1 & 3.2 & 0.3 & 15.0 & 78.5 & 0 & 0 & 2.0 & 1.0 \\
\hline Pf2 & 3.2 & 0.3 & 15.0 & 78.5 & 0 & 0 & 2.0 & 1.0 \\
\hline Pf3 & 3.2 & 0.3 & 15.0 & 78.5 & 2.0 & 1.0 & 0 & 0 \\
\hline
\end{tabular}

Table 6

RECIPES USED TO

PREPARE AQUEOUS

SUSPENSIONSOF

FLORFENICOL

Carrying out the grinding process in the presence of ethoxylated castor oil promotes lower average particle diameter compared to grinding in the presence of sunflower oil.

The surfactant compounds used to stabilize aqueous suspensions of praziquantel and florfenicol are 20 EO polyethoxylated sorbitan monooleate (Tween 80), sodiumlauryl-ether-sulfate (EMAL), ethoxylated propoxylated C12C14 fatty alcohol (Alc1) and C12-C14 fatty alcohol ethoxylate (Alc 2).

The aqueous suspensions of praziquantel were prepared according to the recipes shown in table 5. For the Pp1 sample, vegetable sunflower oil was used in the preparation of the organic phase, and for the Pp2 and Pp3 samples, the ethoxylated castor oil was used.

The aqueous suspensions of florfenicol were prepared according to the recipe shown in table 6 . The oil phase used for the Pf1 sample to prepare the aqueous suspension of the medication was sunflower oil, and for Pf2 and Pf3 samples was ethoxylated castor oil.

\section{Determination of suspension stability}

Evaluation of the stability of the prepared suspensions was performed over a $14 \mathrm{~h}$ period, recording between 5 and 14 curves for each sample. The transmission and blackscattering profiles of the praziquantel suspensions (Pp1, Pp2, Pp3) are shown in figures 6-8.

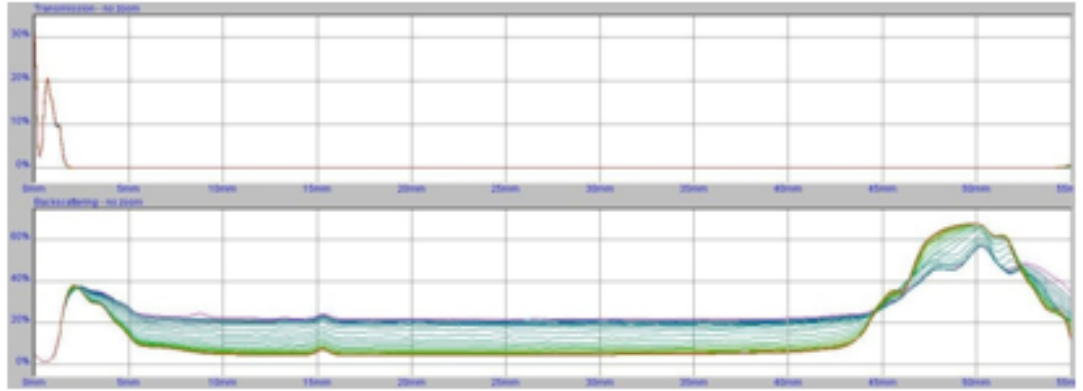

Fig. 6. Stability profiles for sample Pp1

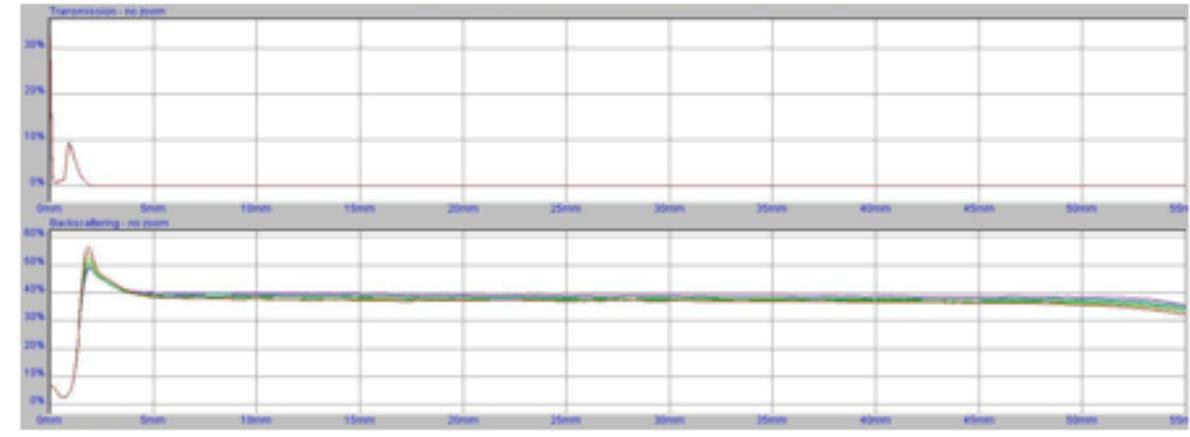

Fig. 7. Stability profiles for sample Pp2 


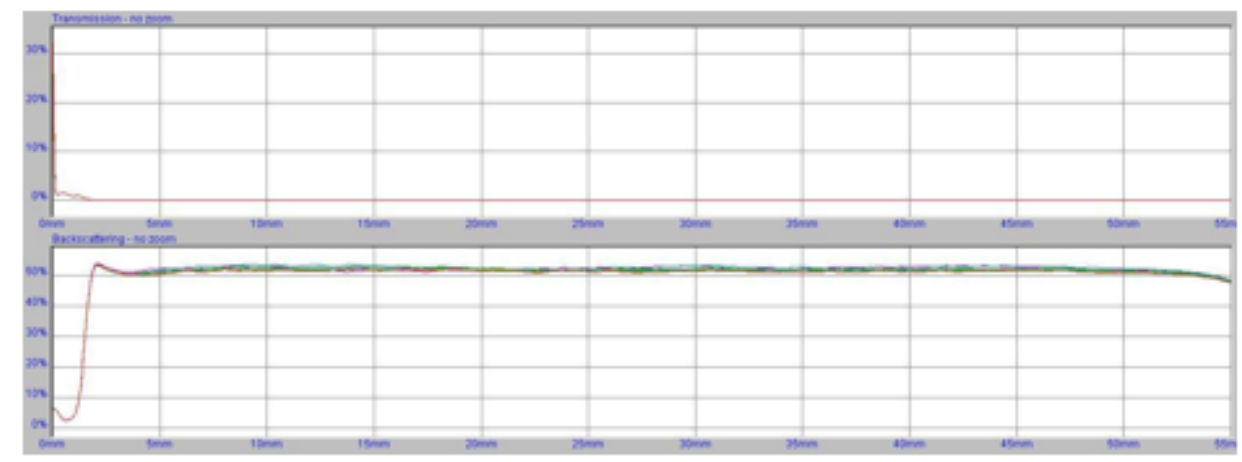

Fig. 8. Stability profiles for sample Pp3

A total overlap of the transmission curves is observed while the diffusion curves differ over the entire period studied, which demonstrates that the suspension of praziquantel based on sunflower oil is unstable over time (fig. 6).

In the case of the ethoxylated castor oil Pp2 sample, a total overlap of the transmission curves and an almost complete overlap of the diffusion curves over the entire period studied was observed, which demonstrates that the praziquantel based on ethoxylated castor oil is relatively stable (fig. 7).

Total overlap of the transmission and diffusion curves was observed over the entire study period, demonstrating that the praziquantel resin-based ethoxylated castor oil suspension in the presence of 20 EO polyethoxylatedsorbitanmonooleate surfactants and ethoxylatedpropoxylated C12-C14 fatty alcohol is stable (fig. 8).

The transmission and diffusion profiles of florfenicol suspensions (Pf1, Pf2, Pf3) are shown in figures 9-11.
An almost complete overlap of the transmission curves is observed while diffusion curves differ throughout the studied period, demonstrating a phase separation immediately after preparation, showingthat the suspension of florfenicol based on sunflower oil is unstable in time (fig. 9).

In the case of Pf2 sample based on ethoxylated castor oil (fig. 10), a total overlap of the transmission curves and an almost complete overlap of the diffusion curves over the entire studied period is observed, with a tendency for separation which becomes more evident towards the area of the suspension sample. This separation tendency demonstrates that the ethoxylated castor oil-based florfenicol suspension prepared in the presence of the sodium lauryl sulfate surfactant mixture and the ethoxylated C12-C14 fatty alcohol has a low stability.

In the case of ethoxylated castor oil-based florfenicol suspension in the presence of $20 \mathrm{EO}$ polyethoxylate dsorbitanmonooleate surfactants and ethoxylate-
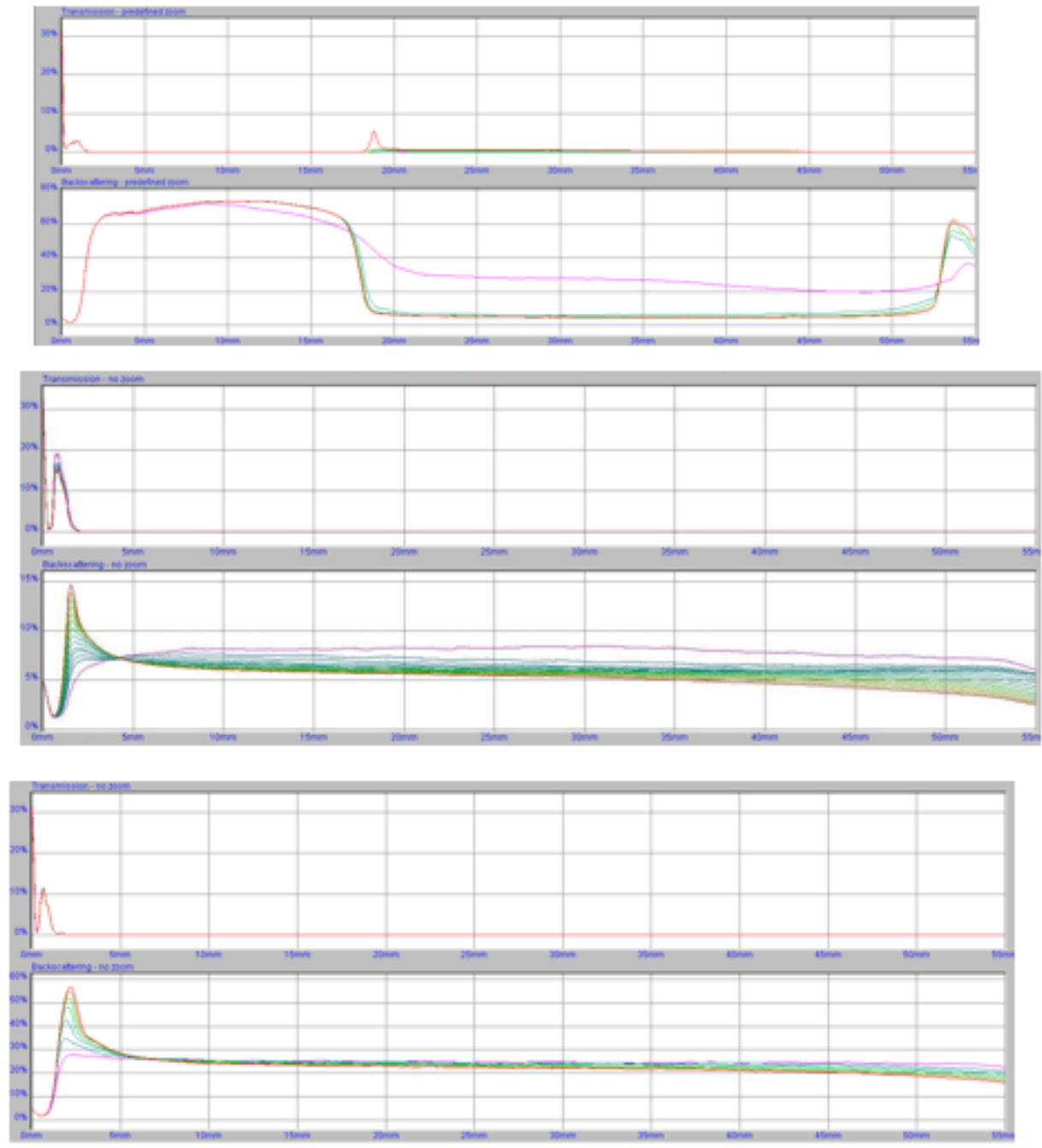

Fig. 9. Stability profiles for sample Pf1

Fig. 10. Stability profiles for sample Pf2

Fig. 11. Stability profiles for sample Pf3 
dpropoxylated C12-C14 fatty alcohol (fig. 11), a total overlap of the transmission curves over the entire period studied. The diffusion curves show a tendency for separation that points to the upper area of the suspension sample, demonstrating that the florfenicol suspension based on ethoxylated castor oil in the presence of 20 EO polyethoxylatedsorbitan mono-oleate surfactants and ethoxylated C10-C12 fatty alcohol -propoxylate is partially stable.

\section{Conclusions}

Suspensions of praziquantel and florfenicol based on sunflower oil have a low stability.

The use of polyoxyethylene (20) sorbitan monooleate in the presence of ethoxylated castor oil in the preparation of praziquantel and florfenicol suspensions has improved the stability of these suspensions.

Suspensions of praziquantel prepared in the presence of ethoxylated castor oil have a better stability than those of florfenicol.

This PZQ and FFC preparation can be used in the treatment of parasitic/bacterial heterologous coinfections.

The suspension of the PZQ and FFC preparation can be administered by water-diffusion, having a controlled release. The compounds are biodegradable and the route of administration remains safe for the environment.

We think this study would help create a more effective formula of PZQ and FFC in treating monogenic infestations in fish and their bacterial coinfections.

\section{References}

1.BANDILLA, M., VALTONEN, E.T., SUOMALAINEN, L.R., APHALO, P.J ., HAKALAHTI, T., A link between ectoparasite infection and susceptibility to bacterial disease in rainbow trout, Int. J. Parasitol, 36, 2006, p.986-990.

2.BAKALETZ, L.O., Developing animal models for polymicrobial diseases, Nat. Rev. Microbiol, 2, 2004, p. 552-568.

3.BOWERS, J.M, MUSTAFA, A., SPEARE, D.J., CONBOY, G.A., BRIMACOMBE, M., SIMS, D.E., BURKA, J.F., The physiological response of Atlantic salmon, Salmo salar L., to a single experimental challenge with sea lice Lepeophtheirus salmonis, J. Fish Dis., 23,2000, p.165172.

4.BURKA, J.F., HAMMELL, K.L., HORSBERG, T.E., JOHNSON, G.R., RAINNIE, D.J., SPEAKERS, D.J., Drugs in salmonid aquaculture - A review, J. Vet. Pharmacol. Therap., 20, 1997, p.334-348.

5.BYLUND, G., SUMARI, O., Laboratory tests with Droncit against diplostomiasis in rainbow trout, Salmo gairdneri Richardson, J. Fish Dis., 4,1981, p.259-64.

6.*** Cox, F.E.G., Concomitant infections, parasites and immune responses, Parasitology, 122 (23-S38),2001.
7.HIRAZAWA, N., MITSUBOSHI, T., HIRATA, T., SHIRASU, K., Susceptibility of spotted halibut Verasper variegatus (Pleuronectidae) to infection by the monogenean Neobenedenia girellae (Capsalidae) and oral therapy trials using praziquantel, Aquaculture, 238, 2004, p.84-94.

8.HIRAZAWA, N., AKIYAMA, K., UMEDA, N., Differences in sensitivity to the anthelmintic praziquantel by the skin-parasitic monogeneans Benedenia seriolae and Neobenedenia girellae, Aquaculture, 404405, 2013, p.59-64.

9.HOLZER, A.S., SOMMERVILLE, C., WOOTTEN, R., Molecular studies on the seasonal occurrence and development of five myxozoans in farmed Salmo trutta L. Parasitology, 132, 2006, p.192-204.

10.J OHNSON, P.T., HOVERMAN, J.T., Parasite diversity and coinfection determine pathogen infection success and host fitness, Proc. Natl Acad. Sci. U.S.A., 109, 2012, p.9005-9012

11.PAPICH, MARK, G., Saunders Handbook of Veterinary Drugs (Fourth Edition), 2016.

12.MICHEL, C., KEROUAULT, B., MARTIN, C., Chloramphenicol and florfenicol susceptibility of fish-pathogenic bacteria isolated in France: comparison of minimum inhibitory concentration, using recommended provisory standards for fish bacteria, J. Appl. Microbiol., 95(5), 2003, p.1007-1014.

13.MITCHELL, A.J., Importance of treatment duration for praziquantel used against larval digenetic trematodes in sunshine bass, J. Aquat. Anim. Health,7, 1995, p.327-30.

14.NORDMO, R., HOLTH RISETH, J.M., VARMA, K., SUTHERLAND, H.I., BROKKEN, E.S, Evaluation of florfenicol in Atlantic salmon, Salmo salar L.: effivacy against furunculosis due to Aeromonas salmonicida and cold water vibriosis due to Vibrio salmonicida, J. Fish Dis.,21, 1998, p.288-296.

15.POYNTON, S.L., CAMPBELL, T.W., PALM, H.W., Skin lesions in captive lemon sharks Negaprion brevirostris (Carcharhinidae) associated with the monogenean Neodermophthirius harkemai Price, 1963 (Microbothriidae), Diseases of Aquatic Organisms, 31(1), 1997, p.28-32.

16.SAMUELSEN, O.B., BERGH, Ø., Efficacy of orally administered florfenicol and oxolinic acid in the treatment of Vibriosis in cod (Gadus morhua L.),Aquaculture, 235, 2004,p. 26-37.

17.SANMARTIN DURAN, M.L., CAAMANO-GARCIA, F., FERNANDEZ CASAL, J., LEIRO, J., UBEIRA, F.M., Anthelminthic activity of praziquantel, niclosamide, netobimin and mebendazole against Bothriocephalus scorpii naturally infecting turbot (Scophthalmus maximus), Aquaculture, 76,1989, p.199-201.

18.SITJA-BOBADILLA, A., DE FELIPE, M.C., ALVAREZ PELLITERO, P., In vivo and in vitro treatments against Sparicotyle chrysophrii (Monogenea:Microcotylidae) parasitizing the gills of gilthead sea bream (Sparus aurata L.),Aquaculture, 261, 2006, p.857-863.

19.WILLIAMS, R.E., ERNST, I., CHAMBERS, C.B., WHITTINGTON, I.D., Efficacy of orally administered praziquantel against Zeuxapta seriolae and Benedenia seriolae (Monogenea) in yellowtail kingfish Seriola lalandi, Diseases of Aquatic Organisms, 77, 2007, p.197-203.

Manuscript received: 19.11.2018 